UDC 343.13

LBC 67.410 .212

\title{
MODERNIZATION OF THE SYSTEM OF PRE-TRIAL PROCEEDINGS IN CRIMINAL PROCEDURE
}

\author{
Ilya S. Dikarev \\ Volgograd State University, Volgograd, Russian Federation
}

Introduction: the article raises the question whether the system of pre-trial proceeding corresponds to the modern functionality of the investigator and prosecutor, who are not joined any more by corporate communication and general procedural functions after the reform of pre-trial proceedings of 2007. The purpose of the study is to elucidate the necessity of changing the system of pre-trial proceedings in criminal cases. Methods: this has applied the scientific methods of analysis and synthesis, the system approach, the methods of legal interpretation and logical and legal one. The methodological framework is the dialectical method. The result of this research is the conclusion that the stage of preliminary investigation does not have internal unity in the modern conditions. Its forming stages - the criminal investigation by the investigator and the activities of the prosecutor on the criminal case received with the indictment - have different (mismatched) signs that clearly indicates the invalidity of combining these phases into a single stage. Each of these corresponds to the signs of an independent stage of criminal procedure. Conclusions: the system of pre-trial proceedings is in need of modernization through the separation of activities of the prosecutor on the preliminary investigation of the criminal case received with the outcome document into a separate stage of criminal procedure. This stage is proposed to call the sending of the criminal case by the prosecutor to court. The appropriate changes need to be made in the criminal procedure legislation.

Key words: criminal procedure, stage of criminal procedure, preliminary investigation, prosecutor, investigator, indictment, public prosecutor's supervision.

УДК 343.13

ББК 67.410 .212

\section{МОДЕРНИЗАЦИЯ СИСТЕМЫ ДОСУДЕБНОГО ПРОИЗВОДСТВА В УГОЛОВНОМ ПРОЦЕССЕ}

\author{
Илья Степанович Дикарев \\ Волгоградский государственный университет, г. Волгоград, Российская Федерация
}

\begin{abstract}
Введение: в статье ставится вопрос о соответствии системы досудебного производства современному функционалу следователя и прокурора, которых после реформы досудебного производства 2007 г. больше не объединяют корпоративная связь и общие процессуальные функции. Цель исследования состоит в выяснении необходимости изменения системы досудебного производства по уголовным делам. Методы: для этого применялись общенаучные методы анализа и синтеза, системный подход, метод юридической интерпретации и логикоюридический метод. Методологической базой послужил диалектический метод. Результатом исследования стал вывод о том, что стадия предварительного расследования в современных условиях не обладает внутренним единством. Образующие ее этапы - расследование уголовного дела следователем и деятельность прокурора по поступившему к нему с обвинительным заключением уголовному делу - характеризуются различными (несовпадающими) признаками, что прямо указывает на необоснованность объединения этих этапов в рамках одной стадии. Каждый из них соответствует признакам самостоятельной стадии уголовного процесса. Выводы: система досудебного производства нуждается в модернизации за счет выделения деятельности прокурора по поступившему к нему с итоговым документом предварительного расследования уголовному делу в самостоятельную стадию уголовного процесса. Эту стадию предлагается именовать направлением уголовного дела прокурором в суд. Соответствующие изменения необходимо внести и в уголовно-процессуальное законодательство.

Ключевые слова: система уголовного процесса, стадия уголовного процесса, предварительное расследование, прокурор, следователь, обвинительное заключение, прокурорский надзор.
\end{abstract}




\section{Введение}

Общим местом уголовно-процессуальной теории является выделение в системе досудебного производства по уголовным делам двух стадий: возбуждения уголовного дела и предварительного расследования. При этом процессуальная деятельность прокурора по уголовному делу, поступившему к нему с обвинительным заключением (актом, постановлением), традиционно рассматривается как элемент стадии предварительного расследования (хотя в юридической литературе уже давно отмечаются проблемы с определением данного этапа в стадийном построении уголовного процесса $[4$, с. 18]). Этой традиции следует и законодатель, включивший главу 31 «Действия и решения прокурора по уголовному делу, поступившему с обвинительным заключением» в раздел VIII УПК РФ, названный «Предварительное расследование», а ст. 226 («Решение прокурора по уголовному делу, поступившему с обвинительным актом») и ст. 226.8 («Решения прокурора по уголовному делу, поступившему с обвинительным заключением») - соответственно в главы 32 и 32.1 УПК РФ, регламентирующие порядок производства дознания.

\section{Система досудебного производства в условиях изменившихся процессуальных отношений прокурора и следователя}

Надо сказать, что в модели досудебного производства, предусмотренной ранее действовавшим законодательством (имеется в виду уголовно-процессуальное законодательство до внесения в него изменений Федеральным законом от 5 июня 2007 г. № 87-Ф3), рассмотрение действий и решений прокурора по уголовному делу, поступившему к нему с обвинительным заключением, как части стадии предварительного расследования - его завершающего, кульминационного этапа, было вполне логичным. Ведь деятельность следователя и дознавателя по установлению обстоятельств совершенного преступления находилась, по выражению В.Л. Будникова, в общей канве осуществляемого прокурором уголовного преследования, и это позволяло с полным основанием говорить о «корпоративности» уголовного преследования и досудебного производства [1]. На предварительном расследовании прокурор был полноправным процессуальным руководителем, который мог не только давать следователю обязательные для исполнения указания, но и лично участвовать в производстве предварительного расследования. Так что утверждение прокурором обвинительного заключения было не чем иным, как принятием и оценкой руководителем результата работы, выполненной процессуально подчиненным ему следователем.

Реформа досудебного производства 2007 г. коренным образом изменила такое положение. Жесткая демаркация процессуальных функций следователя и прокурора в досудебном производстве привела к тому, что последний утратил возможность руководить производством предварительного следствия и непосредственно участвовать в нем, превратившись во внешнего надзирателя, который вправе требовать от органов предварительного расследования устранения нарушений федерального законодательства, но вмешиваться в производство предварительного следствия уже не может.

Однако все эти преобразования парадоксальным образом никак не отразились на системе досудебного производства. Организация предварительного расследования осталась неизменной, и прокурор, как и прежде, на завершающем этапе данной стадии не просто включается в процессуальную деятельность, но по сути сменяет следователя, становясь органом, ведущим производство по уголовному делу. Такая модель несовместима с современным функционалом следователя и прокурора, которых больше не объединяет корпоративная связь. И это явно свидетельствует о незавершенности реформы досудебного производства, которая непременно должна была затронуть систему уголовного процесса.

\section{Предварительное расследование с точки зрения признаков стадии уголовного процесса}

В теории уголовного процесса выделяется совокупность признаков, характеризующих тот или иной этап уголовного судопроиз- 
водства как самостоятельную стадию. К таким признакам принято относить: непосредственные задачи, подлежащие решению на данной стадии; круг субъектов уголовно-процессуальной деятельности; специфику процессуальной формы осуществления такой деятельности; итоговые процессуальные решения, которыми завершается стадия. В данных признаках, с одной стороны, проявляется единство процессуальной деятельности, составляющей содержание отдельной стадии уголовного процесса, где каждый ее этап, каждая часть образует элемент целостной системы, а с другой - выражается специфика отдельной стадии, присущие ей особенности, передающие неповторимый характер и отграничивающие ее от других стадий уголовного судопроизводства.

Анализ процессуальной деятельности, осуществляемой на paзнblx этапах стадии предварительного расследования, приводит к выводу о том, что они характеризуются абсолютно разными признаками: действия и решения прокурора по уголовному делу, поступившему с обвинительным заключением, разительно отличаются от всей предшествующей деятельности следователя по расследованию уголовного дела.

В науке уголовного процесса не выработано единого мнения относительно задач предварительного расследования, однако совершенно очевидно, что эти задачи всегда формулируются исследователями применительно прежде всего к деятельности следователя. Так, например, Ю.К. Якимович и Т.Д. Пан в качестве задач предварительного расследования назвали: 1. Быстрое и полное раскрытие и расследование преступлений. 2. Своевременное привлечение лиц, по мнению следователя, виновных в совершении преступления, в качестве обвиняемых, собирание доказательств и оказание содействия в собирании доказательств участникам со стороны защиты так, чтобы их было достаточно для рассмотрения дела в суде. 3. Возмещение причиненного преступлением материального ущерба или создание условий для его возмещения [6, с. 122-123]. Характеризуя с различной степенью полноты процессуальную деятельность следователя, названные задачи, очевидно, не имеют непосредственного отно- шения к деятельности прокурора на завершающем этапе предварительного расследования. По уголовному делу, поступившему к нему с обвинительным заключением, прокурор выполняет функцию надзора за процессуальной деятельностью органов предварительного следствия. Основной задачей данного этапа является тотальная проверка исполнения закона в стадиях возбуждения уголовного дела и предварительного расследования, осуществляемая посредством ревизии всех материалов уголовного дела, оценки доказательств в их совокупности, сопоставления их с выводами, сформулированными следователем в обвинительном заключении [2, с. 29]. Такая проверка нацелена на выяснение вопроса о возможности направления уголовного дела в суд. Таким образом, задачи, решаемые на разных этапах стадии предварительного расследования, различны.

Существенно различным является и состав участников рассматриваемых этапов стадии предварительного расследования. По сути, на данной стадии уголовного процесса производство по делу ведут последовательно два разных субъекта - сначала следователь, затем прокурор.

Конечно, уголовный процесс допускает замену должностного лица/органа, ведущего уголовный процесс, когда это связано с необходимостью соблюдения правил подследственности или подсудности. Но в таких ситуациях замена субъекта не влияет на сущность и форму осуществляемой процессуальной деятельности. Например, выяснив на стадии назначения судебного заседания, что уголовное дело не подсудно суду, в который оно поступило, судья выносит постановление о направлении уголовного дела по подсудности (п. 1 ч. 1 ст. 227 УПК РФ). После этого вести уголовный процесс будет судья другого суда, но характер его процессуальной деятельности (и, главное, его процессуальная функция) не изменится: он будет продолжать подготовку к судебному заседанию.

Совсем иная ситуация складывается при направлении уголовного дела с обвинительным заключением прокурору. Последний не продолжает деятельность следователя по расследованию преступления, а решает совсем другие задачи, о которых было сказано выше. 
При этом, направив прокурору уголовное дело с обвинительным заключением, сам следователь перестает быть субъектом процессуальных отношений и по общему правилу больше не участвует в уголовном процессе (за исключением случаев, когда уголовное дело возвращается для производства дополнительного следствия). Прокурор же, заняв положение должностного лица, ведущего производство по делу, вступает в процессуальные отношения с обвиняемым, его защитником, потерпевшим, гражданским истцом, гражданским ответчиком и их представителями.

Существенно отличается и проиессуальная форма осуществления деятельности следователем и прокурором. По поступившему с обвинительным заключением уголовному делу прокурор не занимается собиранием или проверкой доказательств, он не вправе проводить следственные действия, самостоятельно избирать меру пресечения или применять иные меры процессуального принуждения. Его полномочия строго ограничены содержанием ст. 221 УПК РФ, предусматривающей возможность принятия отдельных процессуальных решений, определяющих дальнейшее движение уголовного дела.

Наконец, для каждого из рассматриваемых этапов стадии предварительного расследования законодатель устанавливает различные сроки. Согласно ч. 2 ст. 162 УПК РФ в срок предварительного следствия включается время со дня возбуждения уголовного дела и до дня его направления прокурору с обвинительным заключением или постановлением о передаче уголовного дела в суд для рассмотрения вопроса о применении принудительных мер медицинского характера. Сроки принятия решения прокурором по поступившему к нему с обвинительным заключением уголовному делу установлены в ч. 1 и 1.1 ст. 221 УПК РФ.

Таким образом, анализ процессуальной деятельности в стадии предварительного расследования приводит к выводу о том, что данная стадия не обладает внутренним единством. Составляющие ее этапы - расследование уголовного дела следователем и деятельность прокурора по уголовному делу, поступившему с обвинительным заключени- ем, - характеризуются различными (несовпадающими) признаками, что прямо указывает на необоснованность их объединения в рамках одной стадии.

\section{Выделение стадии направления}

\section{уголовного дела в суд как средство модернизации досудебного производства}

По нашему мнению, действия и решения прокурора по уголовному делу, поступивщему к нему с итоговым документом предварительного расследования, необходимо рассматривать как самостоятельную стадию уголовного процесса, которую следует именовать "стадией направления уголовного дела прокурором в суд».

Идея обособить рассматриваемый этап досудебного производства в качестве самостоятельной стадии уголовного процесса высказывалась в процессуальной теории и ранее. В частности, об этом писали Н.С. Манова и Ю.В. Францифоров. Однако в их позиции вызывает возражение предложение рассматривать данную стадию как предание обвиняемого суду [3, с. 36]. Представляется, что вопросы предания суду должны относиться к компетенции суда, поскольку обвинительный порядок в силу его необъективности не может обеспечивать должный уровень гарантий права личности не оказаться под судом без достаточных к тому оснований. Выделяет стадию окончания предварительного расследования и А.А. Резяпов, но при этом он включает в ее структуру ознакомление участников уголовного процесса с материалами уголовного дела и передачу уголовного дела прокурору, которые осуществляет орган предварительного расследования [5, с. 10 , 17]. Таким образом, на данной стадии оказываются двое лидирующих субъектов сначала следователь, а затем прокурор, что лишает единства выделяемый этап судопроизводства.

Как уже было сказано, стадия направления уголовного дела прокурором в суд должна включать в себя только деятельность прокурора по поступившему к нему уголовному делу. При этом принципиально важно, что в новых условиях, то есть после разде- 
ления в досудебном производстве процессуальных функций органов расследования и прокурора, выделение данной стадии стало не просто возможным, но необходимым. В этом смысле досудебное производство нуждается в модернизации, то есть в изменениях сообразно требованиям современности. Ситуация, когда в одной и той же стадии уголовного процесса производство по делу ведут последовательно два субъекта, выполняющие совершенно различные процессуальные функции, противоречит основам стадийного построения российского уголовного судопроизводства.

\section{Сопутствующие изменения структуры уголовно-процессуального законодательства}

В связи с изложенным было бы целесообразно изменить и структуру уголовно-процессуального законодательства. Все нормативноправовые предписания, регламентирующие действия и решения прокурора по поступившим к нему для направления в суд уголовным делам, должны быть сосредоточены в отдельном разделе VIII.1 УПК РФ (входящем во вторую часть УПК РФ, озаглавленную «Досудебное производство»). Речь идет о нормах, содержащихся ныне в главе 31 УПК РФ, ст. 226 и ст. 226.8 УПК РФ. Что касается нормативно-правовых предписаний, регламентирующих направление в суд уголовных дел для применения иных мер уголовно-правового характера (ч. 1 ст. 427 , ч. 5 ст. 439 и ч. 2 ст. 446.2 УПК РФ), то их местоположение в УПК РФ менять не следует, однако содержание нуждается в совершенствовании. Очевидным недостатком действующего уголовно-процессуального законодательства является отсутствие в нем требования направлять через прокурора в суд уголовные дела для применения принудительных мер воспитательного воздействия и назначения меры уголовно-правового характера в виде судебного штрафа. В настоящее время такие дела попадают к прокурору лишь в том случае, если расследование проводится в форме дознания (ч. 1 ст. 427 , ч. 2 ст. 446.2 УПК РФ). Такая регламентация, во-первых, противоречит общему правилу о том, что обратиться к судебной власти с требованием о привле- чении лица к уголовной ответственности или о применении иной уголовно-правовой меры вправе только прокурор, обладающий монопольным полномочием на поддержание в суде государственного обвинения и ходатайств о применении иных мер уголовно-правового характера, а во-вторых, выводит возбуждаемые следователем перед судом ходатайства о применении принудительной меры воспитательного воздействия и о назначении меры уголовноправового характера в виде судебного штрафа из-под надзора прокурора.

\section{Выводы}

Реформа досудебного производства 2007 г. не была доведена до логического завершения: проведенное законодателем жесткое разграничение процессуальных функций следователя и прокурора никак не отразилось на системе уголовного процесса. Эти участники уголовного процесса, как и прежде, сменяя друг друга, ведут производство по уголовному делу в рамках единой стадии уголовного процесса - предварительного расследования. Анализ признаков стадии уголовного процесса в их приложении к предварительному расследованию позволяет обнаружить, что эта стадия не обладает внутренним единством. Действия и решения прокурора по уголовному делу, поступившему к нему с итоговым документом предварительного расследования, необходимо рассматривать как самостоятельную стадию уголовного процесса, которую предлагается именовать «стадией направления уголовного дела прокурором в суд». В этой связи в структуре досудебного производства предлагается выделять не две (как сейчас), а три стадии:

1) возбуждение уголовного дела;

2) предварительное расследование;

3) направление уголовного дела прокурором в суд.

Предложенный доктринальный подход необходимо сопроводить структурными изменениями уголовно-процессуального законодательства, важнейшим из которых должно стать введение во вторую часть УПК РФ раздела VIII.1, озаглавленного как «Направление уголовного дела прокурором в суд». 


\section{СПИСОК ЛИТЕРАТУРЫ}

1. Будников, В. Л. Корпоративность досудебного уголовного производства / В. Л. Будников // Адвокатская практика. - 2007. - № 4. - С. 22-25.

2. Дикарев, И. С. Спорные вопросы организации досудебного производства по уголовным делам / И. С. Дикарев // Российская юстиция. - 2016. № 5. - С. 27-30.

3. Манова, Н. С. Процессуальная природа деятельности прокурора при окончании досудебного производства / Н. С. Манова, Ю. В. Францифоров // Российский следователь. - 2003. - № 8. - С. 35-37.

4. Манова, Н. С. Стадии и производства в структуре уголовного процесса / Н. С. Манова // Вестник СГАП. - 2001. - № 3. - С. 17-21.

5. Резяпов, А. А. Окончание предварительного расследования с обвинительным заключением (актом, постановлением) и направление уголовного дела в суд : автореф. дис. ... канд. юрид. наук / Резяпов Айдар Айратович. - Челябинск, 2014. - 30 с.

6. Якимович, Ю. К. Досудебное производство по УПК Российской Федерации (участники досудебного производства, доказательства и доказывание, возбуждение уголовного дела, дознание и предварительное следствие) / Ю. К. Якимович, Т. Д. Пан. -СПб. : Юридический центр Пресс, 2003. 297 c.

\section{REFERENCES}

1. Budnikov V.L. Korporativnost dosudebnogo ugolovnogo proizvodstva [The Corporatism of Pre-
Trial Criminal Proceedings]. Advokatskaya praktika, 2007, no. 4, pp. 22-25.

2. Dikarev I.S. Spornye voprosy organizatsii dosudebnogo proizvodstva po ugolovnym delam [Controversial Issues of Pre-Judicial Proceedings on Criminal Cases]. Rossiyskaya yustitsiya, 2016, no. 5, pp. 27-30.

3. Manova N.S., Frantsiforov Yu.V. Protsessualnaya priroda deyatelnosti prokurora pri okonchanii dosudebnogo proizvodstva [The Procedural Nature of the Prosecutor's Activities at the End of Pre-Trial Proceedings]. Rossiyskiy sledovatel, 2003, no. 8, pp. 35-37.

4. Manova N.S. Stadii i proizvodstva v strukture ugolovnogo protsessa [Stages and Proceedings in the Structure of the Criminal Process]. Vestnik SGAP, 2001, no. 3, pp. 17-21.

5. Rezyapov A.A. Okonchanie predvaritelnogo rassledovaniya s obvinitelnym zaklyucheniem (aktom, postanovleniem) i napravlenie ugolovnogo dela v sud: avtoref. dis. ... kand. yurid. nauk [The End of the Preliminary Investigation with Indictment (Statement, Decision) and Sending the Criminal Case to Court. Cand. jurid. sci. abs. diss.]. Chelyabinsk, 2014, 30 p.

6. Yakimovich Yu.K., Pan T.D. Dosudebnoe proizvodstvo po UPK Rossiyskoy Federatsii (uchastniki dosudebnogo proizvodstva, dokazatelstva $i$ dokazyvanie, vozbuzhdenie ugolovnogo dela, doznanie $i$ predvaritelnoe sledstvie) [Pre-Trial Proceedings in the Criminal Procedure Code of the Russian Federation (The Participants of the Pre-Trial Proceedings, Evidence, Criminal Investigation, Inquiry and Preliminary Investigation)]. Saint Petersbourg, Yuridicheskiy tsentr Press Publ., 2003. 297 p.

\section{Information about the Author}

Ilya S. Dikarev, Doctor of Juridical Sciences, Associate Professor, Director of the Institute of Law, Volgograd State University, Prosp. Universitetsky, 100, 400062 Volgograd, Russian Federation, iliadikarev@volsu.ru.

\section{Информация об авторе}

Илья Степанович Дикарев, доктор юридических наук, доцент, директор института права, Волгоградский государственный университет, просп. Университетский, 100, 400062 г. Волгоград, Российская Федерация, iliadikarev@volsu.ru. 